\title{
O que aprendemos com a pandemia da COVID-19: reflexões e vivencias de uma enfermeira
}

\author{
What we learned from the COVID-19 pandemic: reflections and experiences of a nurse \\ Lo que hemos aprendido de la pandemia de COVID-19: reflexiones y experiencias de \\ una enfermera
}

Recebido: 01/03/2021

Aprovado: 05/08/2021

Publicado: 14/10/2021

\author{
Yeda Aparecida de Oliveira Duarte ${ }^{1}$ \\ Luciana Mitsue Sakano Niwa ${ }^{2}$ \\ Pamella Cristina de Carvalho Lucas ${ }^{3}$ \\ Carla de Lima Silva ${ }^{4}$ \\ Shirley da Rocha Afonso 5
}

O presente artigo tem por objetivo refletir sobre o que se aprendeu com a pandemia da COVID-19. 0 método utilizado foi o teórico-reflexivo baseado em literatura nacional, internacional e na vivência de campo. As considerações se baseiam em três áreas temáticas: Vivenciar a COVID-19; O impacto para os idosos; e $A$ Enfermagem Gerontológica. 0 vivenciar a pandemia apresenta a vivencia de uma enfermeira especialista em enfermagem gerontogeriátrica e mostra o assistir na pandemia, seu processo de contaminar-se, bem como o retorno assistencial em um necessário se reinventar. No impacto aos idosos tem-se as questões dos isolamento e distanciamento, o idoso vulnerável, a solidariedade, a importância da iniciativa privada, o olhar sobre as instituições de longa permanência e as experiências de idosos na pandemia. Na Enfermagem Gerontológica tem-se que o conhecimento e atualização são necessários e o reafirmar da especialidade na Enfermagem, bem como que o cuidar é um ato significativamente pessoal e compreende assumir a importância da existência do outro.

Descritores: Pandemia; Covid-19; Idoso; Enfermagem.

This article aims to reflect on what has been learned from the COVID-19 pandemic. The method used was the theoretical-reflective one based on literature and on field experience from Brazil and other countries. The considerations are based on three thematic areas: Experiencing COVID-19; The impact for the elderly; and Gerontological Nursing. The experience of the pademic shows the lived experiences of a nurse specialist in gerontogeriatric nursing and shows the assistance in the pandemic, their process of becoming contaminated, as well as the assistance return in a necessary reinvention. The impact on the elderly is the issues of isolation and distancing, the vulnerable elderly, solidarity, the importance of the private initiative, the look at longterm institutions and the experiences of elderly people in the pandemic. In Gerontological Nursing, knowledge and updating are necessary and the reaffirmation of the specialty in Nursing, as well as, that care is a significantly personal act and includes assuming the importance of the existence of the other.

Descriptors: Pandemics; Covid-19; Aged; Nursing.

El presente artículo pretende reflexionar sobre lo aprendido en la pandemia de COVID-19. El método teóricoreflexivo utilizado se basó en la literatura nacional e internacional y en la experiencia de campo. Las consideraciones se basan en tres áreas temáticas: Vivenciar el COVID-19; El impacto para los ancianos; y La Enfermería Gerontológica. Vivir la pandemia presenta la experiencia de una enfermera especialista en enfermería gerontogeriátrica y muestra cómo asistir a la pandemia, su proceso de contagio, así como la vuelta a los cuidados en una necesaria reinvención. En el impacto a los ancianos tiene que las cuestiones del aislamiento y distanciamiento, los ancianos vulnerables, la solidaridad, la importancia de la iniciativa privada, la mirada sobre las instituciones de larga estancia y las experiencias de ancianos en la pandemia. En la Enfermería Gerontológica son necesarios el conocimiento y la actualización, así como la reafirmación de la especialidad en Enfermería, y que el cuidado es un acto significativamente personal que incluye asumir la importancia de la existencia del otro.

Descriptores: Pandemias; Covid-19; Anciano; Enfermería.

1. Enfermeira. Especialista em Gerencia em Salud para Personas Mayores. Especialista em Gerontologia Social. Mestre e Doutora em Enfermagem. Bolsista de Produtividade do CNPQ. Professora Associada da Escola de Enfermagem e da Faculdade de Saúde Pública da Universidade de São Paulo (USP), São Paulo, SP, Brasil. ORCID: 0000-0003-3933-2179 E-mail: yedaenf@usp.br

2. Enfermeira. Especialista em Enfermagem Geronto-Geriátrica. Mestre em Cuidado em Saúde. Doutoranda em Enfermagem em Saúde Coletiva pela Escola de Enfermagem (EE) da USP, São Paulo, SP, Brasil. ORCID: 0000-0002-9342-7454 E-mail: lucianamsn@usp.br

3. Enfermeira. Especialista em Saúde do Adulto e Idoso. Doutoranda em Ciências da Saúde pelo Programa Interunidades em Enfermagem da Escola de Enfermagem da Universidade de São Paulo, Ribeirão Preto, SP, Brasil. ORCID: 0000-0003-3661-3290 E-mail: pamella_lucas@usp.br

4. Enfermeira. Tecnóloga em Gestão de Recursos Humanos. Especialista em Enfermagem Gerontológica. Especialista em Enfermagem Clínica e Cirúrgica. Enfermeira Assistencial no Hospital Sírio Libanês - Unidade Bela Vista, São Paulo, SP, Brasil. ORCID: 0000-0003-2640-9114 E-mail: lima.carla@hotmail.com

5. Enfermeira. Especialista em Enfermagem Gerontológica e Geriátrica. Especialista em Docência na área da Saúde. Especialista em Planejamento, Implementação e Gestão do EAD. Coordenadora de Projetos em Enfermagem no Centro Estadual de Educação Tecnológica Paula Souza - Escola Técnica Estadual Parque da Juventude, São Paulo, SP, Brasil. ORCID: 0000-0003-1824-0451 E-mail: shafonso@yahoo.com.br 


\section{INTRODUÇÃO}

A

Organização Mundial de Saúde decretou em 11 de março de 2020 o mais alto nível de alerta do Regulamento Sanitário Internacional: a pandemia da Covid-19, pela alta disseminação em todo o mundo. A doença é causada pelo novo Coronavírus, denominado SARS-CoV-2, que apresenta manifestação clínica variando de infecções assintomáticas a quadros graves ${ }^{1}$.

Os principais sintomas da doença podem variar de um simples resfriado a uma síndrome gripal e até mesmo uma pneumonia severa. São eles: tosse, febre, coriza, dor de garganta, dificuldade para respirar, anosmia, ageusia, distúrbios gastrointestinais, astenia, hiporexia e dispneia ${ }^{2}$. Em idosos pode cursar com síncope, confusão mental, sonolência excessiva, irritabilidade e inapetência².

0 vírus é transmitido por gotículas e contato direto, indireto (superfícies ou objetos contaminados) ou próximo (faixa de 1 metro). 0 diagnóstico da COVID-19 pode ser: 1) clínico, 2) clínico-epidemiológico, 3) clínico-imagem e 4) laboratorial1,2.

Os grupos de risco são os portadores de doenças crônicas como cardiopatia, diabetes, pneumopatias, doenças neurológicas, obesidade, imunodepressão, asma e outros e, também as pessoas com mais de 60 anos pela fisiologia do envelhecimento com a diminuição da eficácia do sistema imune e diminuição da reserva funcional ${ }^{2,3}$.

Para evitar a disseminação do vírus foram propostas medidas de higiene como lavar as mãos com água e sabão ou álcool em gel a 70\%, usar máscaras faciais, etiqueta de tosse, manter distância de um metro entre as pessoas, não compartilhar objetos de uso pessoal, manter o ambiente limpo e arejado, evitar circulação desnecessária em ruas e o distanciamento social1,2.

Esses fatores mudaram a vida de todas as pessoas do planeta. 0 novo normalmente requer o cumprimento adequado das medidas higiênicas e de distanciamento social. Apesar da doença atingir todas as idades e classes sociais, a pandemia expôs vários problemas antigos como: a desigualdade social, a crise econômica, a falta de acesso aos serviços de saúde, a falta de união e transparência política e das informações.

Por outro lado, a pandemia ensinou a se valorizar profissionais essenciais, dentre eles os da enfermagem; trouxe visibilidade para os idosos, muitas vezes esquecidos pela sociedade; e ações de solidariedade se espalharam por todo o Brasil.

Pessoas perderam parentes e amigos para a doença. Outros, não suportando mais o distanciamento e sem nenhuma intenção, se sentiram culpados por levarem o vírus para os mais próximos. Muitos sobreviveram à pandemia e deram um novo sentido a suas vidas, outros sobreviveram e tiveram sequelas, mas todos vivem tomados pelo medo. Existem ainda os que não se contaminaram e continuam em suas casas à espera da vacina, outros que estão apavorados e deprimidos e, ainda, os que acreditam ser apenas um leve resfriado e outros que negam a existência da pandemia. Diante do exposto, este texto pretende refletir sobre o que aprendeu-se com a pandemia da COVID-19.

\section{MÉTODO}

Este é um texto reflexivo baseado em literatura nacional, internacional e na vivência das autoras. 0 texto discorre sobre o aprendizado que a pandemia trouxe e tece considerações sobre no enfrentamento da pandemia.

\section{RESULTADOS}

Esta reflexão se baseia em três áreas temáticas: Vivenciar a COVID-19; O impacto para os idosos; e A Enfermagem Gerontológica. Também traz como suporte seis publicações, três das quais de agências públicas, como a Organização Pan-americana de Saúde e do Ministério da Saúde. 


\section{DISCUSSÃO}

\section{Vivenciar a COVID-19}

Em 2020 o mundo sem fronteiras se viu confinado como nunca se imaginou. Em 26 de fevereiro de 2020 ocorre a notificação do primeiro caso da COVID $19^{2}$ em território nacional, mais especificamente na cidade de São Paulo e em um hospital de grande porte da rede suplementar de saúde. 0 sistema de saúde nacional fica em alerta para novos casos, prefeitos e governadores iniciam protocolos de isolamento social e fechamento do comércio não essencial na tentativa de evitar a transmissão comunitária do vírus, que em pouco tempo se torna de difícil controle e a curva de contágio inicia uma curva ascendente a cada semana epidemiológica1-3.

0 relato de uma enfermeira especialista em gerontologia que vivenciou (e vivencia) diariamente o cenário assistencial, que se contaminou e se recuperou da COVID-19 contraída no mês de abril de 2020, traz que:

Desde os primeiros casos do novo Coronavírus ainda na Ásia e Europa, observamos no serviço no qual faço parte uma postura diferente dos gestores quanto uso racional de equipamentos de proteção individual e possibilidade de expansão de leitos não antes visto. No entanto, até o primeiro doente ser diagnosticado tudo parece tão remoto $e$ distante que beirava o excesso de zelo.

Em menos de um mês o pronto atendimento começou a receber diversos casos de suspeitos, pessoas que tiveram contato com casos confirmados e diagnósticos da COVID-19. Então tudo se tornou real e a onda que antes vista distante se torna um Tsunami e se inicia uma corrida contra o tempo para adaptar rotinas e criar protocolos de atendimento seguros para o paciente e colaboradores. A dicotomia pública e privada se rompem para unir forças visando a capacitação dos profissionais, a realização de estudos para busca de tratamento e ampliação da capacidade de atendimento dos hospitais.

Na constante tentativa de 'consertar a máquina' em seu pleno funcionamento, os fluxos de acesso foram alterados, colaboradores em grupo de risco foram direcionados a áreas 'limpas', férias antecipadas, setores não assistenciais adotam o sistema de home office e escalas $12 \times 36$ propostas para que os colaboradores fossem menos expostos durante o trajeto casa X trabalho. Todos os setores assistenciais e não assistenciais reaprenderam a executar suas tarefas em pouquíssimo tempo.

Mesmo com total apoio da gestão do serviço e adesão dos colaboradores aos protocolos propostos, muitos de nós foram contaminados e impossível identificar a origem, uma vez que a transmissão já se apresentava comunitária em pouco tempo. Nesse momento, minha equipe e eu vivenciamos o medo constate de ser o próximo a contrair o vírus ou transmitir aos nossos familiares. E o sentimento de impotência ao lutar com algo que não se sabia muito bem como evoluía e que mesmo realizando todas as precauções parecia nos vencer.

Os procedimentos eletivos foram remanejados e a demanda por leitos para o tratamento dos casos complicados do novo Coronavírus crescia inversamente à oferta de colaboradores que se ausentavam por no mínimo 15 dias até a resolução do quadro viral, aprendemos a trabalhar mais com menos e que precisávamos apoiar uns aos outros. $O$ setor de saúde do trabalhador teve papel fundamental nos casos de colegas contaminados tanto no diagnóstico quanto no acompanhamento do tratamento. E eu fui uma das colaboradoras que precisou desse atendimento.

Logo na entrada dos funcionários, um a um, todos ao ter sua temperatura aferida são questionados se apresenta algum sintoma sugestivo, e em uma dessas triagens observei que estava com coriza que associei à um quadro alérgico em um primeiro momento. Fui orientada que caso persistisse o sintoma deveria procurar imediatamente o ambulatório de saúde do colaborador. Seguindo a orientação, realizei coleta de exame e recebo o resultado positivo para COVID-19.

Imediatamente sou afastada das minhas atividades e fico revisitando memórias tentando achar onde possivelmente falhei nas barreiras de proteção, se lavei todas as embalagens de produtos comprados no mercado, se acidentalmente passei a mão nos olhos, enfim, em uma busca em vão que logo é substituída por 'como vou voltar para casa e não contaminar minha família?' Foram 15 dias restrita ao meu quarto, fraca, taquicárdica, sem olfato e nem paladar, em uso de medicações para controle de sintomas, em uma luta diária contra o vírus e a minha própria mente que sabia exatamente cada mecanismo fisiopatológico que estava ocorrendo no próprio corpo.

Nesse momento aprendi que deveria filtrar a overdose de informações que recebia diariamente nas notícias e notas oficiais que me davam e retiravam esperança em poucos minutos. E conforme meu sistema imunológico respondia a agressão sofrida comecei a retomar aos poucos minhas atividades acadêmicas, ajudando a elaborar matérias de orientação sobre a COVID 19 ao público idoso, e mantendo assim a mente ativa e focada em bons pensamentos. 
Ao término do afastamento, ainda em processo de recuperação, retomo minhas atividades assistenciais e me dou conta o quanto as 'cicatrizes' da infecção ainda estavam no meu corpo e mente. Somente após cerca de dois meses que me senti de fato recuperada e no status anterior ao novo Coronavírus. Volto ao meu setor que foi reformulado com novos processos de trabalho e com expressiva mudança do padrão dos pacientes sob meus cuidados.

Os idosos crônicos "pós-covid complicado" se apresentavam ainda mais frágeis, com mais dispositivos invasivos e psicologicamente mais abalados, bem como os familiares que tiveram seu acesso restrito. Nesse momento, a Comissão de Controle de Infecção Hospitalar foi fundamental para conduzir o 'novo normal', e auxiliar no trabalho de conscientização de que ao mesmo tempo que a família tem o papel de apoio ao idoso hospitalizado por COVID 19 ou não, ela pode ser vetor para contaminação do próprio paciente e da equipe assistencial.

A experiência com a COVID-19 permitiu transitar por diversos papeis, desde profissional que atende, a familiar que acompanha aflita a distância seu ente querido por vídeo chamada, a paciente em isolamento domiciliar, a amiga que perde uma irmã de profissão que também estava em combate diário. Pode-se não entender o porquê desse vírus surgir, mas em honra a toda essa guerra travada e aqueles que ficaram no campo de batalha, é nossa obrigação aprender algo com tudo isso, ao menos ser mais solidário. E que daqui alguns anos a máscara facial não seja só mais um hábito que incorporamos ao cotidiano como o álcool em gel, mas sim, símbolo do cuidado que temos uns com os outros.

\section{O impacto para os idosos}

Diante da pandemia, os olhares foram direcionados a proteção do grupo de risco, dentre eles, os idosos. A primeira repercussão foi a do distanciamento social que mais parecia um aprisionamento. Muitas ações e atitudes preconceituosas contra os idosos emergiram na ocasião, desde proibir a entrada em supermercados a divulgação de informações falsas como a de que os idosos que estivessem nas ruas teriam seus benefícios (aposentadoria, pensão e BPC) cancelados.

Muitos idosos que cuidavam dos netos foram separados e transferidos para outra residência, acarretando tristeza e saudade.

$\mathrm{O}$ isolamento provocou sensação de solidão e abandono aos idosos que moravam sozinhos e viviam em Instituições de Longa Permanência para Idosos (ILPI). A falta de informação sobre quem, quantos e como são os idosos que vivem em ILPI no Brasil e a falta de políticas e um plano de ação diante da pandemia alarmava um possível genocídio de idosos.

Contudo, a pandemia ensinou a enxergar os idosos no sentido de tecer redes e frentes de apoio em favor da vida. Profissionais de diversas áreas do conhecimento se reuniram e formaram a Frente Nacional de ILPI em prol dos idosos com cursos de capacitação para os profissionais que atuavam na área.

A ação bilionária do Projeto "Todos pela Saúde", iniciativa do Banco Itaú Unibanco para o combate da pandemia em diversas frentes, sendo uma delas - e talvez a maior e mais urgente - o apoio às ILPI do país, um exemplo. Com uma equipe de especialistas em saúde pública vinda de diversos setores, o projeto estrutura-se em quatro pilares principais de ação e tem como principal objetivo combater o coronavírus e apoiar as iniciativas de saúde pública do país.

Em seus eixos, estão sendo trabalhadas ações que viabilizam o cuidado dos envolvidos em cada unidade ajudada. A saber, os quatro eixos se constituem em: a) Informar (fornecer esclarecimentos para a população acerca da COVID-19 e orientar o uso correto e oportuno de máscaras de proteção); b) Proteger (oferecer equipamentos de proteção individual e orientar as ações de cuidado e prevenção); c) Cuidar (ofertar equipamentos hospitalares e testar a população, além de servir como apoio na construção de Centros de Acolhimento), e d) Retomar (apoiar pesquisas epidemiológicas para o tratamento da COVID-19 e instruir gestores locais acerca da retomada das atividades).

Certamente a maior ajuda financeira e instrumental que as ILPIs tiveram nesse momento, o apoio do "Todos pela Saúde" tem sido fundamental para que o cenário brasileiro não seja tão devastador quanto o observado no exterior.

As ações, desenvolvidas a partir de protocolos recomendados pela Frente Nacional de Combate ao Coronavírus nas ILPIs (outra iniciativa de sucesso da sociedade civil, composta por uma equipe de especialistas que elaboraram, entre outras diversas atividades, protocolos de atenção e cuidado para as ILPIs), auxiliaram os gestores de ILPIs a organizar a assistência para 
enfrentar a disseminação da pandemia da COVID-19 e diminuir o risco de mortalidade pela vulnerabilidade social e física dos idosos institucionalizados.

Essas iniciativas tão nobres fizeram a diferença entre o viver e o morrer nas ILPIs do Brasil na pandemia. Elas não serão esquecidas por aqueles que mais precisam e que, muito provavelmente, ainda estão aqui por causa do olhar solidário e atencioso de uma sociedade que ainda se preocupa com os seus.

Idosos que moram sozinhos ou acompanhados por outros idosos ganharam visibilidade no comércio digital. Mercados, farmácias, açougues privilegiaram a entrega para idosos. Redes de solidariedade se formaram por todo país na tentativa de ajudar estes idosos.

Em tempos de distanciamento, se aprendeu que os idosos são plenamente capazes de usar tecnologia e percebeu-se como o mundo tecnológico não está preparado para os idosos. Isto pois deveriam levar em consideração as alterações fisiológicas do envelhecimento para compor seus produtos, ajustando especialmente o tamanho das letras, o ajuste ao toque, e outros.

Ainda sobre tecnologia, se aprendeu novas formas de comunicação, como as chamadas de vídeo entre família e amigos e os acompanhamentos de saúde on-line, que foram uma conquista. Muitas inovações ocorreram na tentativa de investir o tempo dos idosos em saúde e bem-estar como o game Cérebro Ativo para exercitar funções neurológicas com jogos, atividades on-line propostas por centros-dia para diminuir a solidão e promover a socialização.

Foi outro aprendizado enxergar o idoso em situação de rua e que se precisava garantir que ele seja cuidado pelo Estado e, ao se deparar com essa realidade, viu-se que muitas políticas ainda estão no papel e já passou a hora do Estado pô-las em prática.

\section{A Enfermagem Gerontológica}

Ao considerar o processo de envelhecimento populacional é importante desenvolver estratégias e ajustes educacionais e assistenciais que atendam a perspectiva de promoção da autonomia e cidadania sociais da pessoa idosa. Portanto, para o Estado é de grande responsabilidade organizar planos estratégicos de ensino e de educação que atendam os direitos fundamentais da sociedade ${ }^{4}$.

São planos direcionados à funcionalidade da pessoa idosa, integrando o cuidado de saúde à uma manutenção da capacidade funcional, além de prevenção de incapacidades. Ações estratégicas devem também prever o impacto financeiro que cerca a pessoa envelhecida e, por vezes, afastada do mercado de trabalho.

Nessa perspectiva, tem-se a percepção da importância de construir sistemas de atendimentos específicos para essa parcela da população. É uma estimativa que estes sistemas podem gerar desafios e oportunidades de adaptação, tanto para as instituições quanto para o idoso.

É preciso compreender que o envelhecimento é dinâmico e multidimensional e está influenciado por fatores coletivos e individuais responsáveis por definir a forma como a pessoa envelhece e, portanto, é importante promover ações resultantes para um processo evolutivo do indivíduo inserido na sociedade ${ }^{4,5}$.

O envelhecimento é um processo natural e previsto em seres vivos e, por isso, necessitase considerar a totalidade funcional para garantir qualidade de vida, seja em situações incapacitantes decorrentes de doenças degenerativas como nas prevenções, recuperação e reabilitação.

São ações estratégicas empregadas a partir dessa consideração e que exigem o desenvolvimento de conhecimentos práticos capazes de subsidiar as etapas de observação, identificação e tomada de decisão para entender e atender as necessidades humanas dessa parcela da população.

Assim, a preocupação com a população envelhecida origina novos espaços profissionais e ocupações funcionais específicas que requerem formação adequada e comportamento social 
especializado ${ }^{4-6}$. Uma prática de atendimento especializado pode promover serviços de solução de problemas para a população idosa.

0 desenvolvimento do mercado de trabalho necessita romper as barreiras que estigmatizam a população idosa. É necessário adquirir conhecimentos específicos para o atendimento, tanto de saúde como social; construir e transformar as formas de comunicação e convivência.

Nesse sentido, os serviços de saúde precisam especializar-se e construir diretrizes fundamentais para assegurar a atenção de saúde coletiva e individual, centrada no envelhecimento, contribuir com ações estratégicas de preservação da autonomia e promover a individualidade do idoso.

A formação profissional exige um credenciamento das especificidades, com competências e habilidades definidas e direcionadas ${ }^{4-6}$. A circunstância da formação de enfermagem gerontológica deve, então, estabelecer um controle próprio para a execução do trabalho direcionado.

A formação em Enfermagem para o atendimento à pessoa idosa deve centrar-se na qualificação especializada, incentivando o desenvolvimento do conhecimento teórico científico específico no processo de envelhecimento e incluindo especificidades da assistência de enfermagem à pessoa idosa.

Os cursos de enfermagem precisam descrever em seus tópicos disciplinares os cuidados integrados à pessoa idosa e apontar a transição do processo de envelhecimento. É fundamental discutir e correlacionar os conceitos teóricos sobre o envelhecimento humano com a prática de enfermagem, estruturando e caracterizando o cuidado especializado.

É preciso estabelecer e relacionar os conhecimentos necessários do profissional de enfermagem e o trabalho gerontológico adequado, objetivando a construção de uma identidade profissional de enfermagem autônoma e essencial para o cuidado à pessoa idosa.

A especialização da ocupação do cuidado à pessoa idosa é determinante para o mercado de trabalho em enfermagem gerontológica, com pretensão de exclusividade para desempenhar a assistência qualificada de enfermagem ${ }^{6}$. Este interesse reservado é próprio para a discussão da ocupação do espaço de trabalho especializado, instituindo uma identidade própria reconhecida e valorizada pela sociedade.

A qualificação da enfermagem para o atendimento especializado em processo de envelhecimento não pode renunciar à institucionalização e a sistematização da aquisição do conhecimento pois a forma como são adquiridos os conhecimentos sobre o processo de envelhecimento e como são preparados os comportamentos profissionais precisa repercutir em aspectos significativos próprios para a atuação de enfermagem.

A atuação da Enfermagem Gerontológica na atenção ao idoso prioriza a promoção, proteção e recuperação, com a participação da família e, por isso, necessita desenvolver práticas educativas de orientação e informação ao familiar e ao responsável pelo cuidado diário do idoso. Deve valorizar a participação da família para o desenvolvimento da autonomia e tomada de decisão de atendimento das necessidades deste idoso, observando e direcionando as ações realizadas.

É fundamental para a Enfermagem Gerontológica compreender sua competência de atuação na promoção, manutenção e recuperação da saúde do idoso, respeitando os aspectos contextuais da vida cotidiana do idoso e envolvendo familiares e responsáveis nos cuidados diários do idoso pois o cuidado ao idoso envolve um processo complexo de ações estruturados nas dimensões definidoras da vida do idoso.

As ações de cuidar representam a direção sobre o grau de preocupação para proporcionar conforto, alívio e satisfação e, portanto, requerem responsabilidade, cooperação e solidariedade de todos os envolvidos no apoio ao idoso ${ }^{4,5}$. Neste sentido, cuidar é um ato significativamente pessoal e compreende assumir a importância da existência do outro. 


\section{CONCLUSÃO}

Diante de uma das crises humanitárias mais perversas da história, a pandemia de COVID-19 deu votos de esperança quando revelou uma sociedade mais solidária e organizada em prol de seu povo. Em meio a um cenário de total desamparo, principalmente proporcionado pelo governo, se observa diversas iniciativas, em maior ou menor grau, oriundas da sociedade civil com intuito de oferecer respostas rápidas e eficazes contra esse drama.

Vivenciar a doença enquanto enfermeira foi uma experiência singular e houve oportunidade para ressignificar e agradecer por cada momento vivido e a cada obstáculo superado.

Trazer visibilidade para os idosos com manifestações de compaixão da sociedade trouxe a possibilidade das pessoas serem melhores, altruístas e com um vislumbre, que precisa ser amplamente trabalhado, da longevidade que aguarda. Politicas devem sair o quanto antes do papel e ir, de fato, à prática.

No ano da enfermagem, esta foi essencial, especialmente a enfermagem gerontológica já que as principais vítimas da COVID-19 são os idosos. Provocações de colegas enfermeiras sobre o que fazer para evitar o genocídio de idosos institucionalizados impulsionaram a formação da Frente Nacional de ILPI.

O Departamento Científico de Enfermagem Gerontológica mobilizou todo o país para a construção de materiais educativos para os idosos e para as (os) colegas enfermeiras (os) de outras especialidades. Não se poderia deixar de mencionar as (os) colegas que ficaram no campo de batalha na incansável guerra contra a pandemia.

A pandemia vai passar e certamente os aprendizados tornarão os humanos e os profissionais de saúde mais fortes, ressignificados e com a certeza de se ter feito o melhor para os idosos, a sociedade e a enfermagem.

\section{REFERÊNCIAS}

1. Organização Pan-Americana de Saúde. Folha informativa COVID-19 - Escritório da OPAS e da OMS no Brasil [Internet]. Brasília, DF: OPAS; 2020 [citado em 26 ago 2020]. Disponível em: https://www.paho.org/pt/covid19

2. Ministério da Saúde (Brasil). Sobre a doença [Internet]. Brasília, DF: Ministério da Saúde; 2020 [citado em 25 ago 2020]. Disponível em: https://coronavirus.saude.gov.br/sobre-adoenca\#o-que-e-covid

3. Ministério da Saúde (Brasil). Ministério da Saúde declara transmissão comunitária nacional [Internet]. Brasília, DF: Ministério da Saúde; 2020 [citado em 25 ago 2020]. Disponível em: https://www.saude.gov.br/noticias/agencia-saude/46568-ministerio-da-saude-declaratransmissao-comunitaria-nacional

4. Rodrigues RAP, Bueno AA, Silva LM, Kusumota L, Almeida VC, Giacomini SBL, et al. O ensino de enfermagem gerontológica nas instituições públicas brasileiras de ensino superior. Acta Paul Enferm. [Internet]. 2018 [citado em 17 ago 2020]; 31(3):313-20. Disponível em: https://www.scielo.br/pdf/ape/v31n3/1982-0194-ape-31-03-0313.pdf. DOI: https://doi.org/10.1590/1982-0194201800044

5. Gil H. Educação gerontológica na contemporaneidade: a gerontagogia, as universidades de terceira idade e os nativos digitais. RBCEH [Internet]. 2015 [citado em 17 ago 2020]; 12(3):21233. Disponível em: http://seer.upf.br/index.php/rbceh/article/view/6005/pdf

6. Kletemberg DF, Padilha MI, Maliska IA, Villarinho MV, Cosa R. O mercado de trabalho em enfermagem gerontológica no Brasil. Rev Bras Enferm. [Internet]. 2019 [citado em 17 ago 2020]; 72(Supl2):97-103. Disponível em: https://www.scielo.br/pdf/reben/v72s2/pt_00347167-reben-72-s2-0097.pdf. DOI: http://dx.doi.org/10.1590/0034-7167-2018-0178 
Editora Associada: Heloísa Cristina Figueiredo Frizzo

\section{CONTRIBUIÇÕES}

Yeda Aparecida de Oliveira Duarte atuou na redação e revisão. Luciana Mitsue Sakano Niwa, Pamella Cristina de Carvalho Lucas e Carla de Lima Silva participaram na concepção, coleta e análise de dados e redação. Shirley da Rocha Afonso contribuiu na concepção, análise dos dados e redação.

\section{Como citar este artigo (Vancouver)}

Duarte YAO, Niwa LMS, Lucas PCC, Silva CL, Afonso SR. 0 que aprendemos com a pandemia da COVID-19: reflexões e vivencias de uma enfermeira. REFACS [Internet]. 2021 [citado em inserir dia, mês e ano de acesso]; 9(4):1023-30. Disponível em: inserir link de acesso. DOI: inserir link do DOI.

\section{Como citar este artigo (ABNT)}

DUARTE, Y. A. O.; NIWA, L. M. S.; LUCAS, P. C. C.; SILVA, C. L.; AFONSO, S. R. O que aprendemos com a pandemia da COVID-19: reflexões e vivencias de uma enfermeira. REFACS, Uberaba, MG, v. 9, n. 4, p. 1023-30, 2021. Disponível em: inserir link de acesso. Acesso em: inserir dia, mês e ano de acesso. DOI: inserir link do DOI.

\section{Como citar este artigo (APA)}

Duarte, Y.A.O., Niwa, L.M.S., Lucas, P.C.C., Silva, C.L., \& Afonso, S.R. (2021). 0 que aprendemos com a pandemia da COVID-19: reflexões e vivencias de uma enfermeira. REFACS, 9(4), 102330. Recuperado em: inserir dia, mês e ano de acesso de inserir link de acesso. DOI: inserir link do DOI. 